\title{
Strategy to modify the crystallization behavior of EVOH32 through interactions with low molecular weight molecules
}

Micaela Vannini,${ }^{a *}$ Paola Marchese, ${ }^{a}$ Annamaria Celli, ${ }^{a}$ Cesare Lorenzetti ${ }^{b}$

${ }^{a}$ Dipartimento di Ingegneria Civile, Chimica, Ambientale e dei Materiali, Via Terracini 28, 40131 Bologna, Italy.

${ }^{\mathrm{b}}$ Tetra Pak SA, Zone Industrielle la Maillarde 2, 1680 Romont, Switzerland

\section{Corresponding Author}

*E-mail: micaela.vannini@unibo.it. Tel: +39-0512090349. Fax: +39-0512090322.

Table S1. Molecular structure of additives mixed to EVOH32, composition and thermal characterization of the blends

\begin{tabular}{|c|c|c|c|c|c|c|c|c|c|}
\hline $\begin{array}{l}\text { Additive } \\
\text { name }\end{array}$ & $\begin{array}{l}\text { Molecular } \\
\text { structure }\end{array}$ & $\begin{array}{l}\text { Blend } \\
\text { code }\end{array}$ & $\begin{array}{l}\text { Amount of } \\
\text { additive } \\
(\mathrm{mol} \%)^{\mathrm{a}}\end{array}$ & $\begin{array}{c}\text { Amount } \\
\text { of } \\
\text { additive } \\
(w t \%)^{b}\end{array}$ & $\begin{array}{c}\mathrm{Tc} \\
\left({ }^{\circ} \mathrm{C}\right)\end{array}$ & $\begin{array}{c}\Delta \mathrm{Hc} \\
\left(\mathrm{J} \mathrm{g}^{-1}\right)\end{array}$ & $\begin{array}{c}\mathrm{Tg} \\
\left({ }^{\circ} \mathrm{C}\right)\end{array}$ & $\begin{array}{l}\mathrm{Tm} \\
\left({ }^{\circ} \mathrm{C}\right)\end{array}$ & $\underset{\left(\mathrm{J} \mathrm{g}^{-1}\right)}{\Delta \mathrm{Hm}^{\prime}}$ \\
\hline \multirow{2}{*}{$\begin{array}{l}\text { succinic } \\
\text { anhydride }\end{array}$} & & SA06 & 0.6 & 1 & 154 & 58 & 61 & 178 & 61 \\
\hline & & $\mathrm{SA} 2$ & 2.5 & 4 & 139 & 37 & 61 & 163 & 45 \\
\hline \multirow{2}{*}{ coumarin } & & $\mathrm{CO} 04$ & 0.4 & 1 & 157 & 64 & 59 & 182 & 74 \\
\hline & & $\mathrm{CO} 5$ & 5.0 & 13 & 151 & 59 & 46 & 177 & 70 \\
\hline \multirow{2}{*}{$\begin{array}{c}\text { D-(-)- } \\
\text { pantolactone }\end{array}$} & & PA04 & 0.4 & 1 & 157 & 65 & 59 & 181 & 77 \\
\hline & & PA5 & 5.0 & 11 & 150 & 59 & 46 & 177 & 67 \\
\hline \multirow{3}{*}{$p$-toluic acid } & & PT04-L & 0.4 & 1 & 158 & 76 & 59 & 181 & 84 \\
\hline & & PT5-L & 5.0 & 12 & 149 & 56 & 46 & 174 & 59 \\
\hline & & PT5-H & 5.0 & 12 & 147 & 56 & 46 & 174 & 61 \\
\hline \multirow[b]{2}{*}{ benzoic acid } & & BA05 & 0.5 & 1 & 158 & 65 & 60 & 182 & 74 \\
\hline & & BA5 & 5.0 & 11 & 148 & 55 & 46 & 174 & 59 \\
\hline $\begin{array}{l}\text { isophthalic } \\
\text { acid }\end{array}$ & & IA2 & 2.5 & 7 & 147 & 57 & 56 & 173 & 67 \\
\hline \multirow[b]{2}{*}{ glycerol } & & GL06 & 0.6 & 1 & 157 & 65 & 58 & 181 & 76 \\
\hline & & GL5 & 5.0 & 8 & 144 & 64 & 39 & 174 & 72 \\
\hline myo-inositol & & IN03 & 0.3 & 1 & 157 & 62 & 59 & 181 & 76 \\
\hline
\end{tabular}




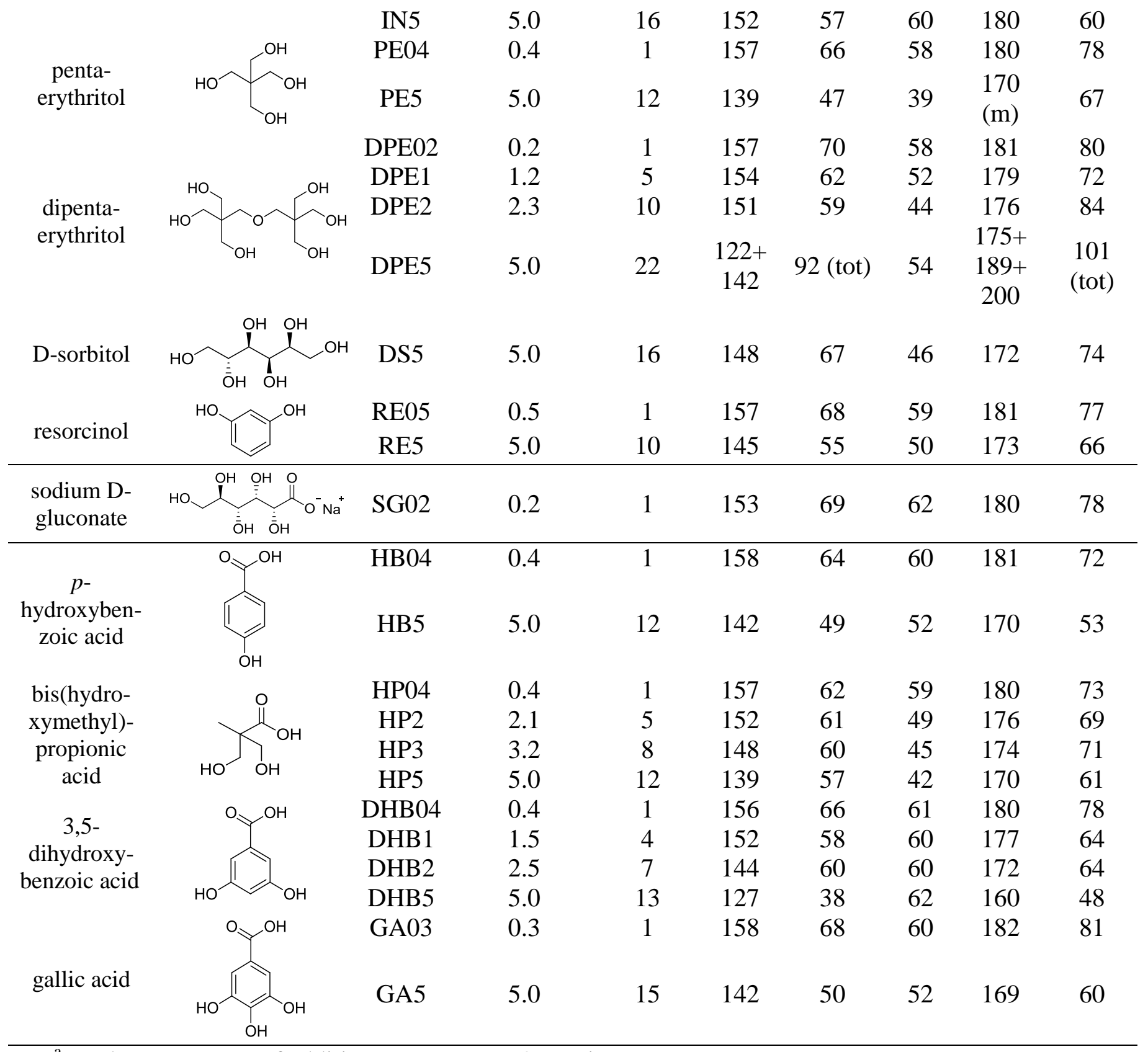

${ }^{\mathrm{a}}$ : molar percentage of additive respect to $\mathrm{PVOH}$ units

${ }^{b}$ : weighted percentage of additive respect to EVOH matrix 